\title{
Antibiotic Therapy for Premature Rupture of Membranes and Preterm Labor and Effect on Fetal Outcome
}

\section{Antiinfektiöse Therapie bei vorzeitigem Blasensprung und Wehentätigkeit und Fetal Outcome}

Author

Affiliation

\section{B. Seelbach-Goebel}

Krankenhaus der Barmherzigen Brüder - Klinik St. Hedwig, Lehrstuhl für Frauenheilkunde und Geburtshilfe der Universität Regensburg, Regensburg

\section{Key words \\ - premature rupture of membranes \\ - impending preterm birth \\ - premature uterine contractions \\ - antibiosis for impending preterm birth \\ Schlüsselwörter \\ - vorzeitiger Blasensprung \\ - drohende Frühgeburt \\ - vorzeitige Wehen \\ - Antibiose bei drohender Frühgeburt}

Deutschsprachige Zusatzinformationen online abrufbar unter: www.thieme-connect.de/ ejournals/toc/gebfra

\section{received $\quad 8.11 .2013$ \\ revised 19.11.2013 \\ accepted 19.11.2013}

Bibliography

Dol http://dx.doi.org/

10.1055/s-0033-1360195

Geburtsh Frauenheilk 2013; 73 :

1218-1227 @ Georg Thieme

Verlag KG Stuttgart · New York . ISSN 0016-5751

\section{Correspondence}

Prof. Birgit Seelbach-Goebel

Lehrstuhl für Frauenheilkunde und Geburtshilfe der Universität Regensburg

Krankenhaus der Barmherzigen Brüder - Klinik St. Hedwig

Frauenklinik

Prüfeninger Straße 86

93049 Regensburg

birgit.seelbach-goebel@

barmherzige-regensburg.de

\section{Abstract \\ $\nabla$}

In Germany almost $10 \%$ of children are born before the end of 37 th week of gestation. In at least one quarter of these cases, ascending infection of the vagina plays a causative role, particularly during the early weeks of gestation. If, in addition to the decidua, the amniotic membrane, amniotic fluid and the umbilical cord are also affected, infection not only triggers uterine contractions and premature rupture of membranes but also initiates a systemic inflammatory reaction on the part of the fetus, which can increase neonatal morbidity. Numerous studies and meta-analyses have found that antibiotic therapy prolongs pregnancy and reduces neonatal morbidity. No general benefit of antibiotic treatment was found for premature uterine contractions. But it is conceivable that a subgroup of pregnant women would benefit from antibiotic treatment. It is important to identify this subgroup of women and offer them targeted treatment. This overview summarizes the current body of evidence on antibiotic treatment for impending preterm birth and the effect on neonatal outcomes.

\section{Introduction}

According to Goldenberg et al. [1], the rate of premature births in Europe is between 5 and 7\%. With almost 500000 premature births annually, the rate in the United States is $12-13 \%$, almost twice that of Europe. In Germany, the rate of premature births is approximately $9 \%$, making Germany one of the European countries with the highest rates of neonates delivered at less than 37 weeks' gestational age [2]. Between 2001 and

\section{Zusammenfassung \\ $\nabla$}

In Deutschland kommen fast $10 \%$ aller Kinder vor Vollendung der 37. Schwangerschaftswoche zur Welt. In mindestens einem Viertel davon spielt eine aszendierende Infektion aus der Vagina eine kausale Rolle, insbesondere in einem niedrigen Gestationsalter. Sind neben der Dezidua die Eihäute, das Fruchtwasser und die Nabelschnur davon betroffen, werden durch entzündliche Prozesse nicht nur Wehen oder ein vorzeitiger Blasensprung ausgelöst, sondern auch eine systemische inflammatorische Reaktion des Fetus selbst in Gang gesetzt, welche die neonatale Morbidität negativ beeinflussen kann. Als Therapiemaßnahme bei vorzeitigem Blasensprung hat sich in zahlreichen Studien und Metaanalysen eine antibiotische Behandlung bewährt, indem die Schwangerschaft prolongiert und die neonatale Morbidität reduziert werden konnte. Bei vorzeitiger Wehentätigkeit hat sich dagegen ein Benefit generell nicht nachweisen lassen. Es ist aber anzunehmen, dass es eine Subgruppe von Schwangeren gibt, die dennoch davon profitieren könnte. Es gilt diese zu identifizieren und gezielt zu behandeln. Die vorliegende Übersicht umreißt die derzeitige Evidenzlage zur antibiotischen Behandlung bei drohender Frühgeburt und zum neonatalen Outcome.

2010 , the rates of extremely premature babies (delivered before the 28th week of gestation [GW]) and preterm neonates (born between the 28th and 32nd GW) increased most (<28 GW: from $0.35 \%$ to $0.6 \%$; $28-32 \mathrm{GW}$ : from $0.7 \%$ to $1 \%$ ). Around one third of premature deliveries are due to premature rupture of membranes, approximately $45 \%$ to premature uterine contractions and the rest to delivery for maternal or fetal indication, e.g. pre-eclampsia or fetal growth restriction. 


\section{Role of Intrauterine Infection \\ $\nabla$}

It is currently assumed that at least every fourth preterm birth is caused by intrauterine infection [3], which develops most commonly through ascension from the vagina or, rarely, via hematogenous routes or per continuitatem (from another focus). Amniocentesis after premature rupture of membranes results in bacterial contamination of amniotic fluid in $30-50 \%$ of cases [4]. Decreasing rates of bacterial colonization ranging from $79 \%$ in the 23 rd week of gestation (GW) to $43 \%$ in the 27 th GW were found in preterm placentas [5].

Infection and inflammation resulting from bacterial ascension to fetomaternal membranes triggers prostaglandin synthesis through elevation of local proinflammatory cytokines and can lead to maternal uterine contractions, a process that also plays a key role in term births. Inflammation of the amnion and chorion is referred to as chorioamnionitis. It is present as a complication in $1-4 \%$ of births; the prevalence of chorioamnionitis is $20-70 \%$ in all preterm births, decreasing to $1-13 \%$ in births at term. While half of all preterm births with a gestational age of 23-24 weeks are associated with chorioamnionitis, it is only present in $5 \%$ of births delivered at a gestational age of more than 37 weeks [6]. Chorioamnionitis is associated with complications in the postnatal period, particularly when diagnosis is based on clinical symptoms (maternal fever $>38^{\circ} \mathrm{C}+$ leukocytosis and/or maternal/fetal tachycardia, uterine tenderness, fetid amniotic fluid) and not only on histological examination of inflammatory changes, e.g. confirmation of infiltration of polymorphonuclear leukocytes and other immune cells such as macrophages and Tcells. Neonatal intraventricular bleeding (IVH), white brain matter injury, bronchopulmonary dysplasia (BPD), necrotizing enterocolitis (NEC) and sepsis have all been associated with histological chorioamnionitis [7-22].

Meta-analyses of clinical case-control and cohort studies have indicated that long-term effects include an increased risk of cerebral palsy [23], with clinical and histological chorioamnionitis associated with periventricular cystic leukomalacia (PVL) [24]. The ELGAN study of 1200 preterm babies born before the 28th week of gestation published in 2010 showed that both histological chorioamnionitis and the detection of microorganisms in the placenta were predictive for ventriculomegaly on neonatal cranial ultrasound and for diparetic cerebral palsy at follow-up after 2 years [25]. However, a recent Canadian study [26] reported that clinical and histological chorioamnionitis were not predictive of neonatal mortality, periventricular leukomalacia or cerebral palsy. Sepsis, bronchopulmonary dysplasia, severe intracranial hemorrhage and retinopathy of prematurity could not be predicted based on the presence or absence of chorioamnionitis.

Evidence would appear to indicate the importance of fetal involvement in the inflammatory process as a pre-condition for neonatal morbidity.

Fetal infection through the umbilical cord or the amniotic fluid triggers an inflammatory immune response (FIRS = fetal inflammatory response syndrome), which is reflected in higher concentrations of interleukin- 6 and other proinflammatory cytokines such as IL $\beta$ and TNF $\alpha$ as well as higher CRP levels and increased leukocyte counts in cord blood [27]. The histological correlates are funisitis and chorial vasculitis.

FIRS is associated with higher neonatal morbidity which can take the form of RDS (respiratory distress syndrome), sepsis, IVH, PVL or NEC [28]. According to a Dutch study of 301 preterm neonates born before 32 weeks of gestation, fetal inflammation (i.e. histo- pathological confirmation of chorial vasculitis, umbilical phlebitis or vasculitis, necrotizing funisitis or concentric umbilical perivasculitis) associated with histologically diagnosed chorioamnionitis had a significant impact on the prevalence of NEC ( 9 vs. $2 \%$; $\mathrm{p}<0.05$ ), IVH ( 25 vs. $12 \%$; $<$ 0.05) and neonatal mortality (19 vs. $9 \%$; $<0.05)$ compared to fetuses without fetal inflammation [29]. A close association between high cytokine levels in amniotic fluid $[21,30]$ and cord blood [31,32] and subsequent cerebral palsy has been reported in several studies.

In a report in the New England Journal published in 2000, Goldenberg et al. [33] provided a comprehensive summary describing ascending infection as a trigger for preterm births and fetal infection. Their representation of bacterial dissemination across fetomaternal membranes has been used ever since to illustrate the pathways of ascending infection.

Numerous unspecific gram-negative and gram-positive microorganisms such as Bacteroides, Fusobacterium, Peptococcus, Peptostreptococcus, Propionibacterium, Pseudomonas, Staphylococcus and Streptococcus and specific organisms from the urogenital tract such as E. coli, Enterobacter, Haemophilus influenzae, Klebsiella pneumoniae, Group B Streptococcus (GBS), Ureaplasma, Mycoplasma hominis, and Neisseria gonorrhoeae have been identified [4].

In an analysis of placental samples from extremely preterm births between the 23rd and 27th GW, positive bacteria cultures were found in $68 \%$ of vaginal births and $41 \%$ of cesarean sections; of these, $30 \%$ of samples had only aerobic bacteria, $21 \%$ had only anaerobic bacteria and $9 \%$ of the culture-positive samples had only Ureaplasma/Mycoplasma [34].

Interest in Ureaplasma urealyticum and Mycoplasma hominis has increased since the 1990s, as they are the most common organisms detected in the amniotic fluid of women with premature rupture of membranes, premature uterine contractions and cervical insufficiency [35-40]. U. urealyticum or M. hominis was detected in cordal blood of 9/84 preterm neonates; funisitis was identified in all of these 9 but only in 13\% of neonates without U. urealyticum or M. hominis ( $p$ 0.001) [41]. Based on the leukocyte count in amniotic fluid, the maternal leukocyte count and CRP, intraamniotic infection with genital Mycoplasma organisms appears to trigger a more intense inflammatory reaction compared to other bacteria [42].

In 351 preterm infants born between the 23rd and 32nd GW, the Alabama Preterm Birth Study identified U. urealyticum or M. hominis in of $23 \%$ samples cultured from umbilical cord blood; this figure increased to $34.7 \%$ for spontaneous preterm deliveries compared to only $3.2 \%$ in indicated preterm deliveries [43].

Infants with cord blood cultures positive for U. urealyticum or M. hominis had significantly higher rates of neonatal systemic inflammatory response syndrome ( 41.3 vs. $25.7 \%$; $=0.007$ ) and bronchopulmonary dysplasia ( 26.8 vs. $10.1 \%$; $=0.0001$ ) compared to infants with negative blood cultures. Neonatal mortality, rates of intraventricular hemorrhage grade 3 and 4, RDS, PVL and NEC did not differ significantly.

In a recent analysis of 126 women with premature uterine contractions, U. urealyticum was identified in $62.7 \%$ und M. hominis in $12.7 \%$ of vaginal swab specimens. In women who had preterm deliveries, vaginal swab specimens were positive for M. hominis in $17.3 \%$ and positive for Ureaplasma in $60.9 \%$ of cases. However in women without premature delivery, specimens were positive for $\mathrm{M}$. hominis in only $3.7 \%$ but positive for Ureaplasma in $53.8 \%$ of cases [44]. Thus the significance of these 

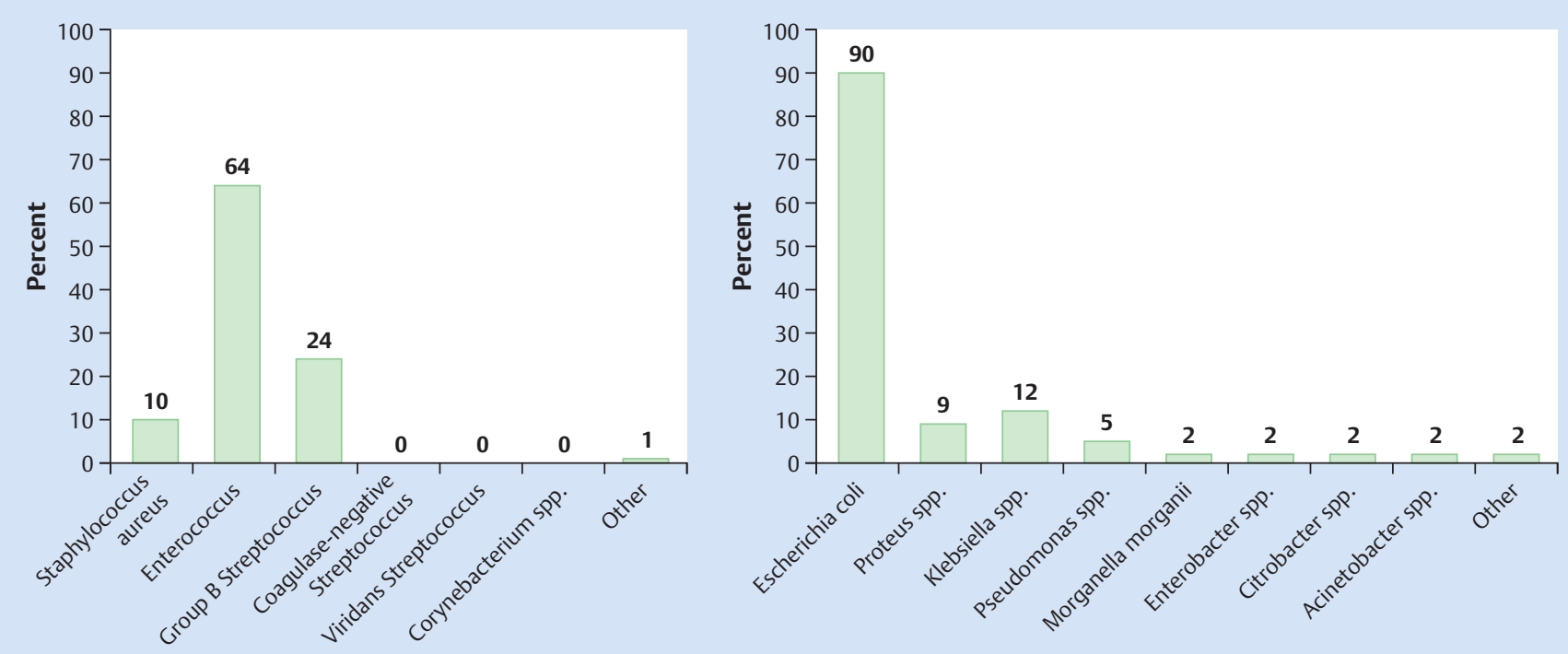

Fig. 1 Percentages for different gram-positive and gram-negative bacteria in vaginal swab cultures obtained from pregnant women with impending preterm birth examined at the University Clinic for Obstetrics and Gynecology St. Hedwig, Regensburg. bacteria as a cause of preterm birth must be qualified. The intravaginal presence of Mycoplasma species and U. urealyticum alone is therefore not sufficient to induce premature birth [45]. Despite the assumed association between Mycoplasma and preterm birth, a randomized American multicenter study showed quite early on that targeted antibiotic therapy with erythromycin vs. placebo in 1181 women with U. urealyticum detected in cultured vaginal specimens offered no benefits with regard to gestational age at delivery, birth weight, Apgar scores and neonatal mortality. Maternal side-effects, nausea and diarrhea occurred significantly more often in the erythromycin-treated group [46]. The Cochrane Review of 2011 came to the conclusion that the current body of evidence does not support antibiotic therapy to prevent preterm birth in pregnant women with vaginal Ureaplasma colonization [47].

Using specially designed DNA probes, organisms were detected in $70 \%$ of amnion or chorion of infants delivered at term by cesarean section [48]. This indicates that the presence of bacteria alone may not always be sufficient to trigger maternal or fetal inflammation [27].

In our own patient cohort of women with impending preterm birth, the most common gram-positive organisms identified in vaginal swabs were Enterococci with a prevalence of $64 \%$, followed by Streptococci B with prevalence of $24 \%$. E. coli was the most commonly found gram-negative species with a prevalence of $90 \%$ ( Fig. 1). Mycoplasma were rarely detected.

The association between intrauterine infection and premature rupture of membranes, premature uterine contractions and neonatal morbidity is the rationale for initiating antibiotic therapy when preterm birth is impending.

The goal of treatment is

1. to prolong the pregnancy to reduce neonatal mortality and morbidity associated with lower gestational age,

2. to prevent infection and inflammation-related neonatal morbidity as a result of (sub)clinical infection of the fetus, and

3. last but not least, to protect the mother from uterine or pelvic infection.

\section{Antibiotics and Premature Rupture of Membranes $\nabla$}

In the last three decades, more than two dozen studies have investigated the efficacy of antibiotic therapy after premature rupture of membranes, and the question has been discussed in structural reviews and meta-analyses since 20 years [4]. The most recent review was published in 2010 and included 22 studies with 6800 women and their infants [49]. The studies included in the review investigated the impact of different antibiotic regimens (penicillins, $\beta$-lactam antibiotics including amoxicillin/clavulanic acid and macrolide antibiotics) administered in different forms and over varying periods in women with premature rupture of membranes between week 20 and week 37; some studies also included multiple pregnancies. The studies also differed with regard to the use of tocolysis and RDS prophylaxis. An overall comparison of all antibiotics used in the studies showed a significantly lower risk for chorioamnionitis compared to placebo (RR 0.66; 95\% CI: 0.46-0.96), a lower risk of delivery within $48 \mathrm{~h}$ and 7 days (RR 0.71; 95\% CI: $0.58-0.8$ and 0.79; 95\% CI: 0.71-0.89, respectively). Neonatal morbidity was also significantly lower in the group which received antibiotic therapy; administration of antibiotics was associated with a reduced risk of neonatal infection (RR 0.67; 95\% CI: 0.52-0.85), lower surfactant use und lower rates of oxygen therapy (RR 0.083; 95\% CI: 0.72-0.96 and RR 0.88; 95\% CI: 0.81-0.96) and lower rates of abnormal cranial ultrasound at discharge (RR 0.81; 95\% CI: 0.68-0.98). However, a sub-analysis showed that the administration of amoxicillin/clavulanic acid was associated with a more than fourfold higher risk of neonatal necrotizing enterocolitis (NEC) (RR 4.72; 95\% CI: 1.57-14.23).

The Cochrane Systematic Reviews have been dominated since 2002 by the British Oracle I Trial [50], which investigated a total of 4826 women and had by far the greatest impact on the results of the meta-analyses, followed by the 1997 study by Mercer et al. [51] with 614 randomized pregnant women.

The Oracle I Trial was carried out between 1994 and 2000 in 161 participating centers located predominantly in the UK. Pregnant 
Table 1 Comparison of the most significant results of the ORACLE I and II Trials.

\begin{tabular}{|c|c|c|c|c|c|c|c|c|}
\hline & \multicolumn{4}{|c|}{ Oracle I $(n=4826)$} & \multicolumn{4}{|c|}{ Oracle II $(n=6295)$} \\
\hline & $\begin{array}{l}\text { Erythro- } \\
\text { myin } \\
1190\end{array}$ & $\begin{array}{l}\text { Co- } \\
\text { amoxi- } \\
\text { clav } \\
1205\end{array}$ & $\begin{array}{l}\text { Erythromycin } \\
+ \text { co-amoxi- } \\
\text { clav } \\
1189\end{array}$ & $\begin{array}{l}\text { Placebo } \\
1225\end{array}$ & $\begin{array}{l}\text { Erythro- } \\
\text { myin } \\
1600\end{array}$ & $\begin{array}{l}\text { Co- } \\
\text { amoxi- } \\
\text { clav } \\
1534\end{array}$ & $\begin{array}{l}\text { Erythromycin } \\
+ \text { co-amoxi- } \\
\text { clav } \\
1551\end{array}$ & $\begin{array}{l}\text { Placebo } \\
1556\end{array}$ \\
\hline \multicolumn{9}{|l|}{ Delivery } \\
\hline$E<48 \mathrm{~h}(\%)$ & 34.9 & 30.5 & 31.3 & 40.7 & 10.4 & 9.9 & 10.7 & 9.8 \\
\hline$E<7 d(\%)$ & 60.9 & 51.7 & 54.4 & 63.3 & 15.8 & 15.4 & 15.1 & 15.2 \\
\hline Maternal antibiotic regimen (\%) & 24.6 & 25.7 & 24.6 & 26.9 & 9.8 & 9.2 & 8.8 & 11,8 \\
\hline Gestational age at delivery (d) & 236 & 236 & 237 & 236 & 267 & 267 & 267 & 266 \\
\hline Birth weight (g) & 2102 & 2083 & 2123 & 2072 & 2823 & 2842 & 2851 & 2857 \\
\hline \multicolumn{9}{|l|}{ Early morbidity } \\
\hline $\operatorname{RDS}(\%)$ & 19.8 & 20.0 & 20.4 & 21.7 & 8.3 & 8.3 & 9.0 & 8.9 \\
\hline Oxygen therapy $\left(>21 \% \mathrm{O}_{2}\right)(\%)$ & 31.1 & 30.1 & 31.1 & 35.6 & 13.6 & 13.2 & 13.5 & 13.3 \\
\hline Use of surfactant (\%) & 14.8 & 15.1 & 14.1 & 17.7 & 5.6 & 5.3 & 5.8 & 5.7 \\
\hline Positive blood culture (\%) & 5.7 & 6.8 & 7.0 & 8.2 & 2.1 & 1.8 & 2.2 & 2.0 \\
\hline NEC (\%) & 0.9 & 1.9 & 1.7 & 0.5 & 0.4 & 0.6 & 0.7 & 0.3 \\
\hline Total morbidity (\%) & 12.7 & 13.5 & 14.0 & 15.2 & 5.6 & 5.0 & 5.9 & 5.0 \\
\hline $\begin{array}{l}\text { Abnormal cerebral ultrasound } \\
(\%)\end{array}$ & 4.2 & 3.8 & 3.9 & 5.0 & 1.6 & 1.8 & 2.2 & 1.9 \\
\hline Mortality (\%) & 5.9 & 6.6 & 6.5 & 6.7 & 2.7 & 2.5 & 3.0 & 2.5 \\
\hline
\end{tabular}

Co-amoxiclav = amoxicillin/clavulanic acid. Figures in Bold indicate significant differences.

Table 2 The most important results of a meta-analysis of 7 randomized controlled trials (RCTs) with i. v. antibiotics administered to women with premature rupture of membranes fewer GW 34 (Mercer 2012): pregnancy outcomes.

\begin{tabular}{|c|c|c|c|}
\hline Pregnancy outcome & $\begin{array}{l}\text { i. v. Antibiosis } \\
n=527\end{array}$ & $\begin{array}{l}\text { Control } \\
n=537\end{array}$ & Significance \\
\hline Prolongation of pregnancy $\geq 7 \mathrm{~d}$ & $46.0 \%$ & $25.9 \%$ & $p<0.00001$ \\
\hline Amnnionitis & $20.5 \%$ & $31.3 \%$ & $p<0.0001$ \\
\hline Cesarean section & $27.5 \%$ & $28.5 \%$ & $p=0.63$ \\
\hline Endometritis postpartum & $10.5 \%$ & $13.0 \%$ & $p=0.21$ \\
\hline
\end{tabular}

Based on Mercer 2012: Antibiotics in the management of PROM [4]

women with premature rupture of membranes were randomized into groups to receive either erythromycin $4 \times$ /day orally or amoxicillin/clavulanic acid $325 \mathrm{mg} 4 \times$ /day orally or erythromycin $250 \mathrm{mg}+$ amoxicillin/clavulanic acid $325 \mathrm{mg}, 4 \times /$ day orally or placebo $4 \times$ /day orally for 10 days or until delivery. Administration of all three antibiotic regimens was associated with a significantly lower rate of deliveries within 48 hours compared to placebo; the administration of amoxicillin/clavulanic acid alone and in combination with erythromycin was additionally associated with a significantly lower rate of deliveries within 7 days. Mean age of gestation and neonatal birth weight were approximately similar for all groups; the prevalence of respiratory distress syndrome, total morbidity and neonatal mortality did not differ significantly between groups. Antibiotic therapy significantly reduced the rates of infants dependent on oxygen, irrespective of the regimen. A significant reduction in positive neonatal blood cultures was only found after administration of erythromycin. A fourfold higher rate of NEC was found in both groups treated with amoxicillin/clavulanic acid ( $\bullet$ Table 1 ).

Because of heterogeneity of previous reviews, in his meta-analysis published in 2012 Mercer [4] only analyzed studies which had exclusively recruited women with premature rupture of mem- branes before GW 34 and which compared broad spectrum antibiotics administered i.v. with controls or placebo [51-57].

With the exception of the study by Mercer et al. in 1997 [51] with 299 and 312 pregnant women, the other studies had only limited case numbers with fewer than 50 patients in the study or control group. The Oracle I Trial was excluded because administration was exclusively oral.

Meta-analysis of the 7 studies showed a higher rate of pregnancy prolongation by more than 7 days ( 46.0 vs. $25.9 \%$ [RR $1.8 ; 95 \% \mathrm{CI}$ : 1.52-2.13]) in the group treated with antibiotics, fewer clinical cases of amnionitis (20.5 vs. $31.3 \%$; RR $0.67 ; 95 \%$ CI: 0.67 [0.54$0.87]$ ), but no changes in the rates of cesarean sections (27.5 vs. $28.5 \%$ ) or endometrisis postpartum ( Table 2 ).

In addition, they found a significant positive effect on neonatal morbidity. Significantly lower rates of sepsis, RDS and IVH were recorded for infants born to mothers treated with broad-spectrum i.v. antibiotics.

Although the prevalence of pneumonia was also half that of the control group, this difference did not reach statistical significance. Rates of NEC, intrauterine fetal death (IUFD) and total survival till discharge were approximately the same for both groups (- Table 3). 
Table 3 The most important results of a meta-analysis of 7 randomized controlled trials (RCTs) with antibiotics administered i. v. to women with premature rupture of membranes before GW 34 (Mercer 2012): neonatal morbidity.

\begin{tabular}{|c|c|c|c|}
\hline \multirow[t]{2}{*}{ Neonatal morbidity } & i.v. Antibiosis group & Controls & Significance \\
\hline & $n=527$ & $n=537$ & \\
\hline Sepsis & $10.9 \%$ & $16.8 \%$ & $p=0.01$ \\
\hline Respiratory distress syndrome (RDS) & $37.9 \%$ & $46.2 \%$ & $p=0.002$ \\
\hline Intraventricular bleeding (IVH) & $12.9 \%$ & $17.8 \%$ & $p=0.02$ \\
\hline Pneumonia & $3.6 \%$ & $6.3 \%$ & $p=0.09$ \\
\hline Necrotizing enterocolitis (NEC) & $8.2 \%$ & $6.9 \%$ & $p=0.45$ \\
\hline Intrauterine fetal death (IUFD) & $0.9 \%$ & $2.7 \%$ & $p=0.2$ \\
\hline Survival rate & $93.7 \%$ & $92.4 \%$ & $p=0.37$ \\
\hline
\end{tabular}

It is still not clear how long antibiotics should be administered. Mercer et al. [51] preferred the administration of amoxicillin $2 \mathrm{~g}$ + erythromycin 250 mg every 6 hours for two days. Subsequently, the pregnant women additionally received $250 \mathrm{mg}$ ampicillin + erythromycin $333 \mathrm{~g}$ orally every 8 hours for 5 days. This regimen was used in a randomized double-blind study undertaken in 11 centers which recruited 614 patients with premature rupture of membranes between GW 24 and GW 32; with this regimen, pregnancy was significantly prolonged compared to placebo (placebo: 2.9 days, antibiosis 6.1 days; $\mathrm{p}<0.001$ ) and the number of births within 48 hours reduced from 36.6 to $27.3 \%$ ( $p<0.03$ ); the number of births within 7 days also dropped from 73.5 to $55.5 \%$ ( $p<0.001)$. The number of women who did not give birth within 14 days increased from $12.1 \%$ without administration of antibiotics to $24.4 \%$ with administration of antibiotics, and the number of women who did not give birth within 21 days increased from 7 to $14.3 \%$.

Total neonatal morbidity was significantly lower, with $44.1 \%$ compared to $52.9 \%(\mathrm{p}=0.04)$. The same applied to rates for sepsis (8.4 vs. $15.6 \% ; \mathrm{p}=0.01$ ), RDS (40.5 vs. $48.7 \%$; $\mathrm{p}=0.04$ ), BPD (13.0 vs. $20.5 \% ; \mathrm{p}=0.01$ ), pneumonia ( 2.9 vs.7\%; $\mathrm{p}=0.04$ ) and NEC levels 2 and 3 ( 2.3 vs. $5.8 \% ; p=0.03$ ). It should also be noted that in this study 116 women who tested positive for Group B Streptococcus infection received $500 \mathrm{mg}$ ampicillin orally for one week and ampicillin i.v. $2 \mathrm{~g}$ every 6 hours intrapartum in addition to the above regimen which was administered after randomization. No significant benefit was found for additional administration of ampicillin.

Shorter administration times for antibiotics were trialed in two smaller studies of women with premature rupture of membranes. The first study with 84 pregnant women compared 3day i.v. administration of ampicillin/sulbactam $3 \mathrm{~g}$ every 6 hours with 7-day administration. No statistical differences were found with regard to duration of pregnancy prolongation (mean for 3day treatment: 137 hours vs. mean for 7-day treatment: 146 hours) or rates of neonatal mortality and morbidity as measured by rates of transfer to the neonatal intensive care unit, RDS, NEC, and IVH level 3 and 4 [58]. The second study with only 48 patients compared 1-day treatment with 5-day treatment consisting of oral ampicillin $500 \mathrm{mg}$ every 6 hours, after prior 2-day i.v. administration of ampicillin $2 \mathrm{~g}, 4 \times$ day. Here too, no significant differences were found in duration of pregnancy prolongation (8 vs. 8.5 days), prevalence of endometritis and chorioamnionitis and neonatal mortality and morbidity rates [59].

The Canadian Guideline [60] recommends penicillins or macrolide antibiotics as the antibiotic of choice, administered intravenously, orally or in combination: either ampicillin $2 \mathrm{~g}+$ erythromycin 250 mg every 6 hours for two days i.v., followed by amoxicil- lin $250 \mathrm{mg}+333 \mathrm{mg}$ erythromycin orally every 6 hours for 5 days or erythromycin $250 \mathrm{mg}$ orally every 6 hours for 10 days.

The German AWMF Guideline 015/029 [61] recommends mezlocillin, piperacillin, clindamycin, ampicillin and erythromycin as suitable antibiotics to treat women with premature rupture of membranes. The Guideline offers no recommendations with regard to the duration of antibiotic treatment. The Guideline is currently being revised.

\section{Antibiotics and Preterm Uterine Contractions \\ $\nabla$}

The clear benefits of antibiotic therapy to treat women with premature rupture of membranes were not mirrored in the existing studies and meta-analyses of women with preterm uterine contractions without rupture of membranes. A few smaller studies from the late 1980s and 1990s reported a significant prolongation of pregnancy after administration of antibiotics to women with preterm uterine contractions [62-67] and a reduction in the number of infants born within 7 days. The prospective randomized placebo-controlled double-blind study of McGregor et al. published in 1986 [62] found a significant prolongation of pregnancy (32.5 vs. 22.4 days; $\mathrm{p}=0.027$ ) in 58 pregnant women with preterm uterine contractions before GW 34 after administration of erythromycin $333 \mathrm{mg}$ orally $3 \times$ /day for 7 days. The same study group also reported a mean prolongation of pregnancy (35 vs. 25 days; $p=0.02$ ) in 117 randomized pregnant women compared to placebo after administration of clindamycin for 3 days i.v. followed by 4 days' oral administration [63]. Moreover, in a subgroup of women positive for bacterial vaginosis, the gestational age at delivery ( $35 \mathrm{vs.} 34 \mathrm{GW}$ ) and the birth weight of the infants were higher (2634 vs. $2256 \mathrm{~g}$ ) in the clindamycin group.

A study in Florida randomized 150 women with cervical dilation of $1 \mathrm{~cm}$ or more and preterm uterine contractions into one of three groups to receive either $500 \mathrm{mg}$ ampicillin orally $4 \times /$ day, $500 \mathrm{mg}$ erythromycin orally $4 \times$ /day or placebo for 10 days. Morales et al. reported a significant delay between admission and delivery after administration of antibiotics (antibiosis: 30 days vs. placebo: 17 days) [64].

In a South African multicenter study [65] 43 patients with preterm uterine contractions between GW 26 and GW 34 were given $1 \mathrm{~g}$ ampicillin i.v. $+1 \mathrm{~g}$ metronidazole as a suppository every 6 hours for 1 day, followed by $3 \times 500 \mathrm{mg}$ amoxicillin per day $+3 \times 400$ g metronidazole per day orally for 5 days. 38 women in the control group received placebo [65].

All women received the tocolytics hexoprenaline and indomethacin together with betamethasone for fetal lung maturation for 24 hours. In patients receiving antibiotics, the pregnancy was sig- 
nificantly prolonged (mean: 15 days vs. 2.5 days, $\mathrm{p}=0.04$ ), and significantly more women were still pregnant at 7 days after admission (63 vs. 37\%; p = 0:04; OR 0.34; 95\% CI: 0.13-0.94). Total infant morbidity (hyaline membrane disease, pneumonia, septicemia, PDA [persistent ductus arteriosus] and NEC) was lower in the group receiving antibiotics ( 24 vs. $39 \%$ ) compared to the placebo group, but the difference was not statistically significant. Five infants in the placebo group and none in the antibiotics group developed NEC ( $\mathrm{p}=0.02)$.

In a Baltic-Scandinavian randomized controlled trial, 59 and 52 pregnant women with preterm uterine contractions between GW 22 and GW 34 were randomized either into an antibiotics group to receive $1 \mathrm{~g}$ ampicillin every 8 hours for 7 days or a placebo group. The mean gestational age at birth in the group receiving antibiotics was significantly higher (36.6 weeks) compared to the placebo group ( 33.8 weeks; $\mathrm{p}<0.05$ ), and the mean birth weight was also significantly higher (2885 vs. $2336 \mathrm{~g}$; $\mathrm{p}$ <0.05). Neonatal infections, intrauterine growth retardation, histological chorioamnionitis and puerperal endometritis-myometritis occurred significantly less frequently in the ampicillintreated group [66].

In a Danish multicenter trial [67], 112 pregnant women with preterm uterine contractions between GW 26 and GW 34 were randomized either into a group treated with $2 \mathrm{~g}$ ampicillin i.v. $4 \times$ daily and $500 \mathrm{mg}$ metronidazole $3 \times$ /day for 24 hours, followed by $500 \mathrm{mg}$ pivampicillin and $400 \mathrm{mg}$ metronidazole for 7 days or into a placebo group. Treatment with antibiotics was associated with a significant prolongation of pregnancy (mean: 47.5 vs. 27 days; $\mathrm{p}<0.05$ ), a higher gestational age at delivery (37 vs. 34 weeks; $\mathrm{p}<0.05$ ) and a lower rate of infants admitted to the neonatal intensive care unit ( 40 vs. $63 \%$; $p=0.03$ ). No statistically significant differences were found in neonatal mortality (no deaths in either group) or morbidity with regard to meningitis, sepsis and pneumonia (10 vs. $22 \%$ ).

In the years that followed, with the exception of a Chilean randomized controlled trial [68], no study on antibiotic treatment for preterm uterine contractions found a significant benefit with regard to prolonged pregnancy and neonatal outcomes, neither with $\beta$-lactam antibiotics, macrolide antibiotics or cephalosporins nor combinations of these drugs [69-74]. Since 2002, metaanalyses have been numerically dominated by the ORACLE II Trial [74]. In analogy to the ORACLE I Trial, 6295 pregnant women with preterm uterine contractions before GW 37 but without rupture of membranes were randomized into 4 groups and received either erythromycin $250 \mathrm{mg} 4 \times$ daily or $325 \mathrm{mg}$ amoxicillin/clavulanic acid $4 \times$ /day or $250 \mathrm{mg}$ erythromycin $+325 \mathrm{mg}$ amoxicillin/clavulanic acid $4 \times$ /day or placebo $4 \times /$ day for 10 days. With the exception of lower rates of maternal infection and a significantly higher rate of NEC in the erythromycin + amoxicillin/ clavulanic acid group, no significant differences were found between groups ( Table 1 ). The most recent update of the Cochrane Systematic Review of 2011 analyzed 11 studies based on 7428 datasets and reported no important new volume of information obtained compared to the meta-analysis of 2002 [75]. In this latest meta-analysis, the ORACLE II Trial dominated as it contributed 6 times as many patients as all other randomized controlled studies combined. In consequence, the authors drew the conclusion that with the exception of reducing maternal infection (RR 0.74; 95\% CI: 0.64-0.87) no benefit could be demonstrated from prophylactic antibiotic treatment for preterm labor without rupture of membranes. However, the large ORACLE II Trial does give some cause for criticism for the following reasons: there is some doubt whether the investigated cohort was even suitable to detect differences between differing forms of treatment.

1. The inclusion of pregnant women in the study depended on the subjective assessment of obstetrician whether uterine contractions were actually preterm labor.

2. On admission, more than half of all women in all randomized groups had cervical dilation of $1 \mathrm{~cm}$ or less. This could be an indication that uterine contractions with cervical dilation were not present and not likely to result in spontaneous birth.

3. Analyses of vaginal swabs and inflammatory parameters were either not carried out or not included in the Oracle II Trial.

4. The mean gestational age at delivery in all groups was around 266 days, i.e. GW 38, a gestational age at which the investigated neonatal morbidities normally only rarely occur.

It is therefore understandable that the Cochrane team limited the core statement of the trial, suggesting that there might be a subgroup of women who would benefit from antibiotic therapy due to the presence of latent infection. The assumption is supported by a study by Ovalle et al. published in 2006 [76], which reported a significantly lower total neonatal morbidity for the group treated with antibiotics compared to the placebo group in a subgroup analysis of women with preterm labor and endocervical inflammation (4\% [1/24] vs. $28 \%$ [7/25]; p < 0.05).

Identifying those women with preterm uterine contractions who have a high risk of preterm delivery is important as this will permit obstetricians to select those pregnant women who would benefit from antibiotic treatment. Vaginal ultrasound to measure cervical length, fetal fibronectin (fFN) test [77], n-ph IGFBP-1 and PAMG-1 tests or combinations of the above are all tools which have a high negative predictive value for preterm delivery within 7 and 14 days. In a recent study from Thailand, the mean test-todelivery time was significantly shorter in women with preterm uterine contractions and a positive PAMG- 1 test compared to women with a negative test ( 20 vs. 720 hours; $p=0.025$ ) [78]. At present, there are no cohort studies of women with preterm uterine contractions given antibiotic therapy selected using one of these tests. A few randomized controlled trials have investigated the efficacy of treatment with erythromycin and metronidazole compared to placebo in women with positive fFN test after fetal fibronectin screening late in the 2nd trimester. However, these studies only investigated pregnant women who were asymptomatic.

An American multicenter study [79] carried out screening for vaginal and cervical fetal fibronectin in 16317 pregnant women between the 21st and 25th week of gestation; 6.6\% of them tested positive. The study group $(n=347)$ received oral antibiotic therapy with metronidazole $250 \mathrm{mg} 3 \times$ daily + erythromycin $250 \mathrm{mg} 4 \times$ daily for 10 days, and the control group $(\mathrm{n}=356)$ received placebo for 10 days. The rate of preterm births was $14.4 \%$ before GW 37, 6.9\% before GW 35 and $4.3 \%$ before GW 32 in the group treated with antibiotics; in the control group the rates were $12.4 \%$ < GW 37 (RR 1.17; 95\% CI: 0.80-1.70), 7.5\% < GW 35 (RR 0.92; 95\% CI: 0.54-1.56) and 2.2\% < GW 32 (RR 1.92; 95\% CI: 0.83-4.52). Neonatal morbidity also did not differ between groups. Among women with prior spontaneous preterm delivery, the rate of repeat spontaneous preterm delivery was significantly higher in the group treated with antibiotics compared to the placebo group (46.7 vs. 23.9\%; $\mathrm{p}=0.03$ ). The PREMET study reached a similar result [80]. Women with a history of previous spontaneous preterm delivery who had a positive fFN test gave birth more often before GW 30 if they had received prior treat- 
ment with oral metronidazole compared to placebo (21 vs. $11 \%$ ) and significantly more often before GW 37 (62 vs. 39\%; RR 1.6; 95\% CI: $1.05-2.4$ ). After approximately 100 women had been recruited, the study was stopped early. In another study, 215 asymptomatic pregnant women between 22 and 26 weeks of gestation who tested positive for bacterial vaginosis (BV) and fetal fibronectin were treated either with $250 \mathrm{mg}$ erythromycin + $250 \mathrm{mg}$ metronidazole $3 \times$ daily for 10 days or placebo. In $77 \%$ of the group treated with antibiotics no bacterial vaginosis was subsequently detected compared to $28.7 \%$ in the placebo group $(\mathrm{p}<0.0001)$. The rate of preterm deliveries < GW 34 in the BVnegative group was significantly lower compared to the group which still tested positive for BV (0 vs. 5.7\%) [81].

\section{Long-Term Outcomes}

$\nabla$

Only infants from the ORACLE I and II Trials have been followed up. The parents of 4148 children from the ORACLE I Trial and of 4221 children from the ORACLE II Trial were interviewed using a standardized questionnaire based on the Multi-Attribute Health Status classification system. Children resident in England were additionally assessed using the results of national curriculum tests done at the age of 7 years. A comparison of the individual regimens of the children in the original ORACLE I Trial showed no significant differences between children of mothers who received antibiotics for preterm rupture of membranes compared to children of mothers who had received placebo with regard to behavioral difficulties, specific medical conditions and educational outcomes [82]. In contrast, children whose mothers with preterm uterine contractions had received erythromycin alone or in combination with amoxicillin/clavulanic acid in the original ORACLE II Trial had more functional impairments than children whose mothers had not received erythromycin (42.3 vs. $38.3 \%$; OR 1.18; 95\% CI: 1.02-1.37) [83]. This was not the case for amoxicillin/clavulanic acid. Surprisingly, there were more cases with cerebral palsy among the children of mothers who had been given erythromycin or amoxicillin/clavulanic acid compared to the children of mothers who had not received these antibiotics (erythromycin: 53/1611 [3.3\%] vs. 27/1561 [1.7\%], OR 1.93, 95\% CI: 1.21-3.09; amoxicillin/clavulanic acid: 50/1587 [3.2\%] vs. 30/ 1586 [1.9\%], OR 1.69, 95\% CI: 1.07-2.67). No significant differences in rates of cerebral palsy were noted for the children of the ORACLE I Trial, neither for erythromycin nor for amoxicillin/ clavulanic acid (erythromycin 2.9 vs. $2.5 \%$, OR 1.18 [0.77-1.81]; co-amoxiclav: 2.4 vs. $2.9 \%$, OR 0.81 [0.53-1.24]) [82]. An analysis of the group with cerebral palsy [84] showed that the majority of cerebral palsy (CP) cases in the ORACLE II Trial (57/80 [71\%]) were children who had been born at more than 32 weeks of gestation, while the majority of CP cases in the ORACLE I Trial (61/87 [60\%]) were children born before 32 weeks of gestation. This surprising result prompted the authors to make the bold suggestion that antibiotic treatment had led to suppression of the infection but not of the inflammation and that the children with cerebral palsy in the ORACLE II Trial might have been exposed to an inflammatory milieu for a longer period of time. Unfortunately the analysis does not show whether other perinatal factors such as perinatal asphyxia could have played a role in the causation of CP. Two analyses investigated the impact of publishing the Oracle I and II Trials in the Lancet in 2001 and of the follow-up study in 2007. Before and after the publication of each study, questionnaires investigating the antibiotic therapy prescribed to women with PROM (preterm premature rupture of membranes) and preterm labor were sent to all obstetric units in the UK. After publication of the ORACLE I and II Trials in the Lancet 2001, almost 50\% of departments changed their antibiotic management: the percentage of patients with PROM who did not receive routine antibiotic treatment dropped from 77 to $41 \%$, the percentage of patients with preterm labor receiving antibiotic treatment rose from 85 to $92 \%$. Erythromycin was prescribed $46 \%$ more often, amoxicillin/clavulanic acid was prescribed $8 \%$ less often [85]. Almost no changes were reported after publication of the follow-up studies in 2007: prior to publication, $2 \%$ did not prescribe antibiotics for premature rupture of membranes, a figure that rose to $4 \%$ after publication; $79 \%$ prescribed antibiotics for preterm labor before publication, rising to $84 \%$ after publication. The majority of clinics (98\%) reported that their antibiotic of choice was erythromycin [86].

The need for caution in the routine prescription of antibiotics for pregnant women with impending preterm birth is supported by reports of increasing rates of E. coli early-onset sepsis in very low birth weight $(<1500 \mathrm{~g}$ ) premature neonates and late-onset sepsis in preterm and term infants. The administration of ampicillin, which is recommended intrapartum for verified GBS infection, was found to be an independent risk factor for ampicillin-resistant E. coli early-onset sepsis in preterm infants [87].

A retrospective Canadian analysis showed that antibiotic resistance in children with early-onset sepsis was associated with maternal exposure to antibiotics, irrespective of whether administration was intrapartum or antepartum [88].

In the last 15 years, prevention of fetal infection has been a dominant goal of obstetrical management. Neonatologists dread sepsis and severe cranial hemorrhage as serious infection-related complications for preterm infants and prefer to deliver infants at a younger gestational age but without infection than at a later age with infection. The literature on the association of neonatal morbidity and intrauterine infection and low gestational age is currently being re-examined [89]. Thus, discussion of the originally postulated causative role of intrauterine infection for chronic lung disease [90] and neonatal white matter disease has now become more nuanced. In a study by Chau et al. published in 2009 [91], histologically verified chorioamnionitis was not considered the primary cause of noncystic white matter injury detected on magnetic resonance imaging of preterm neonates. Rather, postnatal infections and hypotension were associated with a higher risk of white matter injury [91].

Actuated by a fear of fetal infection, we obstetricians do everything in our power to prevent such infections and remove the fetus from the inflammatory environment at the earliest indication.

Unfortunately we have no reliable clinical parameters for fetal involvement which could serve as an indication for preterm artificial induction of labor.

In women with premature rupture of membranes between GW 24 and GW 33, maternal CRP $>20 \mu \mathrm{g} / \mathrm{ml}$ was identified as a simple predictive parameter for funisitis [92]. However, because the body of evidence is insufficient, even the AWMF Guideline does not provide an absolute cut-off for maternal CRP levels and recommends serial controls and delivery of the infant if values continue to rise despite antibiotic treatment.

Persistent inflammation despite antibiotic therapy is reflected in persistently increased maternal interleukin-6 levels, which have an $86.7 \%$ sensitivity and a negative predictive value of $77.8 \%$ for funisitis at a cut-off von $1.98 \mathrm{pg} / \mathrm{ml}$ (specificity: $46.7 \%$, positive 
predictive value 61.9\%) [93]. However in a study published in 2012, Mercer et al. [94] found that in conservatively managed women with preterm premature rupture of membranes (between GW 24 and GW 32), interleukin-6, interleukin-10, G-CSF and ICAM-1 levels in maternal blood were not adequately predictive for neonatal sepsis, IVH level 3-4, NEC level 2-3, RDS, IUFD or neonatal mortality. Only maternal TNF $\alpha$ at delivery was significantly associated with neonatal sepsis prior to discharge. However, significantly higher maternal and umbilical cord blood levels of G-CSF, IL-6 and IL-10 and TNF $\alpha$ were associated with clinical chorioamnionitis. Umbilical cord blood levels of G-CSF and IL6 were significantly increased in neonates who presented with sepsis or another of the above neonatal morbidities within 72 hours of birth. Routine use of cordocentesis to measure these parameters has not become an accepted procedure. Detection of increased levels of these parameters could already be an indication of acute FIRS.

In addition to anti-infectious therapies with antibiotics, another approach, still in its experimental stages, consist in the containment of the fetal inflammatory processes (FIRS) to prevent or reduce typical short and long-term morbidities (sepsis, NEC, BPD, white matter injury, $\mathrm{CP}$ ). Interleukin-10 has a high anti-inflammatory potential and appears to play a role in reducing the inflammatory reaction in women with preterm labor [27,95]. A nonhuman primate study in rhesus monkeys demonstrated that the intra-amniotic administration of interleukin-10 significantly reduced IL- $\beta$-induced uterine contractility [96]. Another study found that i.v. maternal administration of interleukin-10 had a protective effect against white matter injury in new born rat pups [97]. A mouse model also demonstrated that exogenous interleukin-10 can provide neuroprotection against interleukin- $\beta$ induced inflammation [98]. In premature newborns delivered before 28 weeks of gestation, prolonged therapy with the nonsteroidal anti-inflammatory agent indomethacin was associated with less white matter injury on MRI [99].

Our vision for the future is the prolongation of pregnancies with an effective anti-infective and anti-inflammatory therapy which will also reduce neonatal morbidity.

\section{Conclusion}

Despite a number of initially promising studies on the prevention of preterm births through screening for bacterial vaginosis and antibiotic therapy, some also done in Germany [100], the most recent meta-analysis [101] found that antibiotic therapy of asymptomatic pregnant women was not always associated with a significant decrease in preterm delivery. The necessity of a therapeutic regimen for acute impending preterm delivery due to preterm rupture of membranes or preterm uterine contractions remains.

Based on the current body of evidence, treatment with broadspectrum antibiotics and initial intravenous administration is recommended in women with preterm rupture of membranes. Administration until delivery or for a period of 7 days has been found to be effective. The literature to date militates against the routine administration of antibiotics in women with preterm uterine contractions. Nevertheless, a subgroup with subclinical infection/inflammation could benefit from antibiotic therapy. Vaginal swabs for bacterial infection and clinical markers such as maternal CRP and/or interleukin-6 could be included in the decision whether or not to prescribe antibiotics. The identification of particularly high-risk pregnancies may be possible using the fFN test, the PAMG-1 test or n-pH IgfBP-1 test. In future, particularly high-risk groups could be selected through the detection of cytokines and other predisposing genetic polymorphisms.

\section{Conflict of Interest}

$\nabla$

None.

\section{References}

1 Goldenberg RL, Culhane JF, Iams JD et al. Epidemiology and causes of preterm birth. Lancet 2008; 371: 75-84

2 AQUA-Institut für angewandte Qualitätsförderung und Forschung im Gesundheitswesen GmbH. 2011 (a), Gesetzliche Grundlagen §137a SGB V zur „Umsetzung der Qualitätssicherung und Darstellung der Qualität“ im deutschen Gesundheitswesen. Online: http://www.sqg. de/hintergrund/gesetzliche-grundlagen/index.html

3 Muglia LJ, Katz M. The enigma of spontaneous preterm birth. N Engl J Med 2010; 362: 529-535

4 Mercer B. Antibiotics in the management of PROM and preterm labor. Obstet Gynecol Clin North Am 2012; 39: 65-76

5 Onderdonk $A B$, Hecht $L$, Thomas Fet al. Colonization of second trimester placenta parenchyma. Am J Obstet Gynecol 2008; 199: 52.e1-52.e10

6 Tita AT, Anrews WW. Diagnosis and management of clinical chorioamnionitis. Clin Perinatol 2010; 37: 339-354

7 De Felice C, Toti P, Laurini RN et al. Early neonatal brain injury in histologic chorioamnionitis. J Pediatr 2001; 138: 101-104

8 De Felice C, Toti P, Parrini S et al. Histologic chorioamnionitis and severitiy of illess in very low birth weight newborns. Pedriatr Crit Care Med 2005; 6: 293-302

9 Mehta R, Nanjundaswamy S, Shen-Schwarz S et al. Neonatal morbidity and placental pathology. Indian J Pediatr 2006; 73: 25-28

10 Watterberg KL, Demers LM, Scott SM et al. Chorioamnionitis and early lung inflammation in infants in whom bronchopulmonary dysplasia develops. Pediatrics 1996; 97: 210-215

11 Graham EM, Holcroft CJ, Rai KK et al. Neonatal cerebral white matter injury in preterm infants is associated with culture positive infections and only rarely with metabolic acidosis. Am J Obstet Gynecol 2004; 191: 1305-1310

12 Dammann O, Leviton A, Bartels DB et al. Lung and brain damage in preterm newborns. Are they related? How? Why? Biol Neonate 2004; 85: 305-313

13 Salafia CM, Minior VK, Rosenkrantz TS et al. Maternal, placental and neonatal associations with early germinal matrix/intraventricular hemorrhage in infants born before 32 weeks' gestation. Am J Perinatol 1995; 12: 429-436

14 Been JV, Rours IG, Kornelisse RF et al. Histologic chorioamnionitis, fetal involvement, and antenatal steroids: effects on neonatal outcome in preterm infants. Am J Obstet Gynecol 2009; 201: 587.e1-587.e8

15 Andrews WW, Goldenberg RL, Faye-Peterson $O$ et al. The Alabama preterm birth study: polymorphonuclear and mononuclear cell placental infiltrations, other markers of inflammation and outcomes in 23-32 week preterm newborn infants. Am J Obstet Gynecol 2006; 195: 803808

16 Dempsey E, Vhen MF, Kokottis T et al. Outcome of neonates less than 30 weeks' gestation with histologic chorioamnionitis. Am J Perinatol 2005; 22: 155-159

17 Baud 0 , Emilie D, Pelletier E et al. Amniotic fluid concentrations of interleukin-1 beta, interleukin-6 and TNF-alpha in chorioamnionitis before 32 weeks of gestation: histological associations and neonatal outcome. Br J Obstet Gynaecol 1999; 106: 72-77

18 Dexter SC, Pinar H, Malee MP et al. Outcome of very low birth weight infants with histopathologic chorioamnionitis. Obstet Gynecol 2000; 96: $172-177$

19 Tauscher MK, Berg D, Brockmann M et al. Association of histologic chorioamnionitis, increased levels of cord blood cytokines, and intracerebral hemorrhage in preterm neonates. Biol Neonate 2003; 83: 166-170

20 Kaukola T, Herva R, Perhomaa $M$ et al. Population cohort associating chorioamnionitis, cord inflammatory cytokines and neurologic outcome in very preterm, extremely low birth weight infants. Pediatr Res 2006; 59: 478-483 
21 Yoon BH, Jun JK, Romero R et al. Amniotic fluid inflammatory cytokines (interleukin-6, interleukin-1beta, and tumor necrosis factor-alpha), neonatal white matter lesions, and cerebral palsy. Am J Obstet Gynecol 1997; 177: 19-26

22 Lee J, Oh KJ, Yang HJ et al. The importance of intraamniotic inflammation in the subsequent development of atypal chronic lung disease. J Matern Fetal Neonatal Med 2009; 22: 917-923

23 Shatrov JG, Birch SC, Lam LT et al. Chorioamnionitis and cerebral palsy. Obstet Gynecol 2010; 116: 387-392

$24 W u$ YW. Systematic review of choriamnionitis and cerebral palsy. Ment Retard Dev Disabil ResRev 2002; 8: 25-29

25 Leviton A, Allred EN, Kuban KC et al. Microbiologic and histologic characteristics of the extremely preterm infant's placenta predict white matter damage and later cerebral palsy: The ELGAN study. Pediatric Research 2010; 67: 95-101

26 Nasef N, Shabaan A, Schurr P et al. Effect of clinical and histological chorioamnionitis on the outcome of preterm infants. Am J Perinatology 2013; 30: 59-68

27 Romero R, Espinoza J, Goncalves $L F$ et al. The role of inflammation and infection in preterm birth. Semin Reprod Med 2007; 25: 21-39

28 Gomez R, Romero R, Ghezzi F et al. The fetal inflammatory response syndrome. Am J Obstet Gynecol 1998; 179: 194-202

29 Been JV, Zimmermann LJ. Histologic chorioamnionitis and respiratory outcome in preterm infants. Arch Dis Child Fetal Neonatal Ed 2009; 94: F218-F225

30 Yoon BH, Romero R, Park JS et al. Fetal exposure to an intraamniotic inflammation and the development of cerebral palsy at the age of three years. Am J Obstet Gynecol 2000; 182: 675-681

31 Minagawa K, Tsuji Y, Ueda $\mathrm{H}$ et al. Possible correlation between high levels of IL-18 in the cord blood of preterm infants and neonatal development of periventricular leukomalacia and cerebral palsy. Cytokine 2002; 17: 164-170

32 Hansen-Pupp I, Halli AL, Hellstrom-Westas I et al. Inflammation at birth is associated with subnormal development in very preterm infants. Pediatr Res 2009; 64: 183-188

33 Goldenberg RL, Hauth JC, Andrews WW. Intrauterine infection and preterm delivery. N Engl J Med 2000; 342: 1500-1507

34 Onderdonk AB, Delaney ML, DuBois AM et al. Detection of bacteria in placental tissues obtained from extremely low gestational age neonates. Am J Obstet Gynecol 2008; 198: 110.e1-110.e7

35 Romero R, Sirtori M, Oyarzun E et al. Infection and labor. V: Prevalence, microbiology, and clinical significance of intraamnonic infection in women with preterm labor and intact membranes. Am J Obstet Gynecol 1989; 161: 817-824

36 Romero R, Gonzales R, Sepulveda W et al. Infection and labor. VIII. Microbial invasion of the amniotic cavity in patients with suspected cervical incompetence: prevalence and clinical significance. Am J Obstet Gynecol 1992; 167: 1086-1091

37 Romero R, Yoon BH, Mazor $M$ et al. A comparative study of the diagnostic performance of amniotic fluid glucose, white blood cell count, interleukin-6, and gram stain in the detection of microbial invasion in patients with preterm premature rupture of membranes. Am J Obstet Gynecol 1993; 169: 839-851

38 Yoon BH, Romero R, Park JS et al. Microbial invasion of the amniotic cavity with Ureaplasma urealyticum is associated with a robust host response in fetal, amniotic, and maternal compartments. Am J Obstet Gynecol 1998; 179: 1254-1260

39 Yoon BH, Chang JW, Romero R. Isolation of Ureaplasma urealyticum from the amniotic cavity and adverse outcome in preterm labor. Obstet Gynecol 1998; 92: 77-82

40 Lee SE, Romero R, Park CW et al. The frequency and significance of intraamniotic inflammation in patients with cervical insufficiency. Am J Obstet Gynecol 2008; 198: 633.e1-633.e8

41 Egawa T, Morioka I, Morisawa T et al. Ureaplasma urealyticum and Mycoplasma hominis presence in umbilical cord is associated with pathogenesis of funisitis. Kobe J Med Sci 2007; 53: 241-249

$42 \mathrm{Oh} \mathrm{KJ}$, Lee KA, Sohn YK et al. Intraamniotic infection with genital mycoplasmas exhibits a more intense inflammatory response than intraamniotic infection with other microorganisms in patients with preterm premature rupture of membranes. Am J Obstet Gynecol 2010; 203: 211.e1-211.e8

43 Goldenberg RL, Andrews WW, Goepfert AR et al. The Alabama Preterm Birth Study: umbilical cord blood Ureaplasma urealyticum and Mycoplasma hominis cultures in very preterm newborn infants. Am J Obstet Gynecol 2008; 198: 43.e1-43.e5
44 Choi SJ, Park SD, Jang IH et al. The prevalence of vaginal microorganisms in pregnant women with preterm labor and preterm birth. Ann Lab Med 2012; 32: 194-200

45 Capoccia R, Greub G, Baud D. Ureaplasma urealyticum, Mycoplasma hominis and adverse pregnancy outcomes. Curr Opin Infect Dis 2013; 26: 231-240

46 Eschenbach DA, Nugent RP, Rao AV et al. A randomized placebo-controlled trial of erythromycin for the treatment of Ureaplasma urealyticum to prevent premature delivery. The Vaginal Infections and Prematurity Study Group. Am J Obstet Gynecol 1991; 164: 734-742

47 Raynes Greenow CH, Roberts CL, Bell JC et al. Antibiotics for ureaplasma in the vagina in pregnancy. Cochrane Database Syt Rev 2011; 9: CD003767

48 Steel JH, Malatos S, Kennea $N$ et al. Bacteria and inflammatory cells in fetal membranes do not always cause preterm labor. Pediatr Res 2005; 57: 404-411

49 Kenyon S, Boulvain M, Neilson JP. Antibiotics for preterm rupture of membranes. Cochrane Database Syst Rev 2010; 8: CD 001058

50 Kenyon SL, Taylor DJ, Tarnow-Mordi W; ORACLE Collaborative Group. Broad-spectrum antibiotics for preterm, prelabour rupture of fetal membranes: the ORACLE I randomised trial. Lancet 2001; 357: 979988

51 Mercer B, Miodovnik M, Thurnau G et al.; The NICHD-MFMU Network Antibiotic therapy for reduction of infant morbidity after preterm premature rupture of the membranes: a randomized controlled trial. JAMA 1997; 278: 989-995

52 Lockwood CJ, Costigan K, Ghidini A et al. Double-blind placebo-controlled trial of piperacillin prophylaxis in preterm membrane rupture. Am J Obstet Gynecol 1993; 169: 970-976

53 Amon E, Lewis SV, Sibai BM et al. Ampicillin prophylaxis in preterm premature rupture of the membranes: a prospective randomized study. Am J Obstet Gynecol 1988; 159: 539-543

54 Christmas JT, Cox SM, Andrews W et al. Expectant management of preterm ruptured membranes: effects of antimicrobial therapy. Obstet Gynecol 1992; 80: 759-762

55 Fuhr N, Becker C, van Baalen A et al. Antibiotic therapy for preterm premature rupture of membranes: results of a multicenter study. J Perinat Med 2009; 34: 203-206

56 Johnson MM, Sanchez-Ramos L, Vaughn AJ et al. Antibiotic therapy in preterm premature rupture of the membranes: a randomized prospective double-blind study. Am J Obstet Gynecol 1990; 163: 743-747

57 Owen J, Groome LJ, Hauth JC. Randomized trial of prophylactic antibiotic therapy after preterm amnion rupture. Am J Obstet Gynecol 1993; 169: $976-981$

58 Segel SY, Miles AM, Clothier B et al. Duration of antibiotic therapy after preterm premature rupture of fetal membranes. Am J Obstet Gynecol 2003; 189: 799-802

59 Lewis DF, Adair $C D$, Robichaux AG et al. Antibiotic therapy in preterm premature rupture of fetal membranes. Am J Obstet Gynecol 2003; 189: 799-802

60 Yudin MH, van SchalkwykJ, Van Eyck $N$ et al. Antibiotic therapy in preterm premature rupture of membranes. J Obstet Gynaecol Can 2009; 31: 863-867

61 AWMF Leitlinie Nr.015/029 Empfehlungen zum Vorgehen beim vorzeitigen Blasensprung.

62 McGregor IA, French JL, Reller LB et al. Adjunctive erythromycin treatment for idiopathic preterm labour: Results of a randomized, double blinded, placebo-controlled trial. Am J Obst Gynecol 1986; 154: 98103

63 McGregor IA, French I, Seo K. Adjunctive clindamycin therapy for preterm labor: results of a double-blinded placebo-controlled trial. Am J Obstet Gynecol 1991; 165: 867-875

64 Morales WJ, Angel JL, O'Brien WF et al. A randomized study of antibiotic therapy in idiopathic preterm labor. Obstet Gynecol 1988; 72: 829-833

65 Norman K, Pattinson RC, de Souza J et al. Ampicillin and metronidazole treatment in preterm labour: a multicentre, randomised controlled trial. Br J Obstet Gynecol 1994; 101: 404-408

66 Nadisaukiene R, Bergström S, Kilda A. Ampicillin in the treatment of preterm labor: a randomised, placebo-controlled study. Gynecol Obstet Invest 1996; 41: 89-92

67 Svare J, Langhoff-Roos J, Andersen LF et al. Ampicillin-metronidazole treatment in idiopathic preterm labour: a randomised controlled multicentre trial. Br J Obstet Gynaecol 1997; 104: 892-897 
68 Oyarzún E, Gómez R, Rioseco A et al. Antibiotic treatment in preterm labor and intact membranes; a randomized, double-blinded, placebocontrolled trial. J Matern Fetal Med 1998; 7: 105-110

69 Newton ER, Dinsmoor MJ, Gibbs RS. A randomized, blinded, placebocontrolled trial of antibiotics in idiopathic preterm labor. Obstet Gynecol 1989; 74: 562-566

70 Romero R, Sibai B, Caritis S et al. Antibiotic treatment of preterm labour with intact membranes: a multicenter, randomized double blind, placebo-controlled trial. Am J Obstet Gynecol 1993; 169: 764-774

71 Watts DH, Krohn MA, Hillier SL et al. Randomized trial of antibiotics in addition to tocolytic therapy to treat preterm labor. Infect Dis Obstet Gynecol 1994; 1: 220-227

72 Gordon M, Samuels P, Shubert P et al. A randomized, prospective study of adjunctive ceftizoxime in preterm labour. Am J Obstet Gynecol 1995; 172: $1546-1552$

73 Cox SM, Bohman Van R, Sherman ML et al. Randomized investigation of antimicrobials for the prevention of preterm birth. Am J Obstet Gynecol 1996; 174: 206-210

74 Kenyon SL, Taylor DJ, Tarnow-Mordi W et al. Broad-spectrum antibiotics for spontaneous preterm labour: the ORACLE II randomized trial. Lancet 2001; 357: 989-994

75 King J, Flenady V. Prophylactic antibiotics for inhibiting preterm labour with intact membranes. Cochrane Database Syst Rev 2002; 4: CD000246

76 Ovalle A, Romero R, Gómez R et al. Antibiotic administration to patients with preterm labor and intact membranes: is there a beneficial effect in patients with endocervical inflammation? J Matern Fetal Neonatal Med 2006; 19: 453-464

77 Peaceman AM, Andrews WW, Thorp JM et al. Fetal fibronectin as a predictor of preterm birth in patients with symptoms. Am J Obstet Gynecol 1997; 177: 13-16

78 Sukchaya K, Phupong $V$. A comparative study of positive rate of placental alpha-microglobulin 1 test in pre-term pregnant women with and without uterine contraction. J Obstet Gynaecol 2013; 33: 566-568

79 Andrews WW, Sibai BM, Thom EA et al. Randomized clinical trial of metronidazole plus erythromycin to prevent spontaneous preterm delivery in fetal fibronectin-positive women. Obstet Gynecol 2003; 101 847-855

80 Shennan A, Crawshaw S, Briley A et al. A randomized controlled trial of metronidazole for the prevention of preterm birth in women positive for cervicovaginal fetal fibronectin: the PREMET Study. BJOG 2006; 113: $65-74$

81 Hendler J, Andrews WW, Carey CJ et al. The relationship between resolution of asymptomatic bacterial vaginosis and spontaneous preterm birth in fetal fibronectin-positive women. Am J Obstet Gynecol 2007; 197: 488.e1-488.e5

82 Kenyon S, Pike K, Jones DR et al. Childhood outcomes after prescription of antibiotics to pregnant women with preterm rupture of the membranes; 7-year follow-up of the ORACLE trial. Lancet 2008; 372: 1310-1318

83 Kenyon S, Pike K, Jones DR et al. Childhood outcomes after prescription of antibiotics to pregnant women with spontaneous preterm labour: 7-year follow-up of the ORACLE II trial. Lancet 2008; 372: 1319-1327

84 Marlow N, Pike K, Bower E et al. Characteristics of children with cerebral palsy in the ORACLE children study. Dev Med Child Neurol 2012; 54: 640-646
85 Kenyon S, Taylor DJ. The effect of the publication of a major clinical trial in a high impact journal on clinical practise: the ORACLE Trial experience. BJOG 2002; 109: 1341-1343

86 Kenyon S, Pike K, Jones $D$ et al. Has publication of the results of the ORACLE Children Study changed practice in the UK? BJOG 2010; 117: $1344-1349$

87 Bizarro MJ, Dembry LM, Baltimore RS et al. Changing patterns in neonatal Escherichia coli sepsis and ampicillin resistance in the era of intrapartum antibiotic prophylaxis. Pediatrics 2008; 121: 689-696

88 Wright AJ, Unger S, Coleman BL et al. Maternal antibiotic exposure and risk of antibiotic resistance in neonatal early-onset sepsis: a case-cohort study. Pediatr Infect Dis J 2012; 31: 1206-1208

89 Thomas W, Speer CP. Chorioamnionitis: important risk factor or innocent bystander for neonatal outcome? Neonatology 2011; 99: 177187

90 Lahra MM, Beeby PJ, Jeffery HE. Intrauterine inflammation, neonatal sepsis, and chronic lung disease: a 13-year hospital cohort study. Pediatrics 2009; 123: 1314-1319

91 Chau V, Poskitt KJ, McFadden DE et al. Effect of chorioamnionitis on brain development and injury in premature newborns. Ann Neurol 2009; 66: 155-164

92 Perrone G, Anceschi MM, Capri O et al. Maternal C-reactive protein at hospital admission is a simple predictor of funisitis in preterm premature rupture of membranes. Gynecol Obstet Invest 2012; 74: 9599

93 Canzeroni BJ, Grotegut CA, Swamy GK et al. Maternal serum interleukin-6 levels predict impending funisitis in preterm premature rupture of membranes after completion of antibiotics. J Matern Fetal Neonat Med 2012; 25: 1329-1332

94 Mercer BM, Crouse DT, Goldenberg RL et al. The antibiotic treatment of PPROM study: systemic maternal and fetal markers and perinatal outcomes. Am J Obstet Gynecol 2012; 206: 145.e1-145.e9

95 Gotsch F, Romero R, Kusanovic JP et al. The anti-inflammatory limb of the immune response in preterm labor, intra-amniotic infection/inflammation, and spontaneous parturition at term: A role for interleukin-10. J Matern Fetal Neonat Med 2008; 21: 529-547

96 Sadowsky DW, Novy MJ, Witkin SS et al. Dexamethasone or interleukin-10 blocks interleukin-1beta-induced uterine contractions in pregnant rhesus monkeys. Am J Obstet Gynecol 2003; 188: 252-263

97 Rodts-Palenik S, Wyatt-Ashmead J, Pang Y et al. Maternal infection-induced white matter injury is reduced by treatment with interleukin10. Am J Obstet Gynecol 2004; 191: 1387-1392

98 Mesples B, Plaisant F, Gressens P. Effects of interleukin-10 on neonatal excitotoxic brain lesions in mice. Brain Res Dev Brain Res 2003; 141 25-32

99 Miller SP, Mayer EE, Clyman RI et al. Prolonged indomethacin exposure is associated with decreased white matter injury detected with magnetic resonance imaging in premature newborns at 24-28 weeks' gestation at birth. Pediatrics 2006; 117: 1626-1631

100 Hoyme UB, Saling E. Efficient prematurity prevention is possible by $\mathrm{pH}$-self measurement and immediate therapy of threatening ascending infection. Eur J Obstet Gynecol Reprod Biol 2004; 10: 148-153

101 Brocklehurst P, Gordon A, Heatley E et al. Antibiotics for treating bacterial vaginosis in pregnancy. Cochrane Database Syst Rev 2013; 1 : CD000262 